One $c c .=0.00606$ gram zinc.

One cc. $=0.00384$ gram manganese.

If the ratio were exactly four zinc to three manganese, using the most recent atomic weights, the strength of this solution against manganese would be one cc. $=0.00382$ gram, while, according to Wyrouboff, $10 \mathrm{Mn}=9 \mathrm{~K}_{4} \mathrm{Fe}(\mathrm{CN})_{6}$ and $6 \mathrm{Zn}=$ ${ }_{4} \mathrm{~K}_{4} \mathrm{Fe}(\mathrm{CN})_{6}$, or $10 \mathrm{Mn}=13.5 \mathrm{Zn}$, or $\mathrm{IMn}=\mathrm{I} .35 \mathrm{Zn}$, and the strength against manganese would be I $c c .=0.003774$ gram.

These figures show but little difference between the two ratios and while $\mathrm{Mr}$. Stone's experimental results are undoubtedly accurate, this theory based on the formation of $\mathrm{Zn}_{9} \mathrm{Fe}(\mathrm{CN})_{8}$ and $\mathrm{Mn}_{3} \mathrm{Fe}_{2}(\mathrm{CN})_{12}$ is not satisfactorily proved.

This article is only a preliminary note regarding the composition of the ferrocyanides as they are being investigated in this laboratory.

In connection with the ferrocyanide of zinc I have found a very strong solution of hydrochloroplatinic acid, $\mathrm{H}_{2} \mathrm{PtCl}_{6}$, acidified with hydrochloric acid, a most satisfactory indicator for the titration of zinc by potassium ferrocyanide, when performed in a hot solution. This indicator is used in the same way as uranium acetate and is less affected by a varying amount of hydrochloric acid. The end reaction is a bright emerald green, which takes a few seconds to develop. It will not work with a cold solution.

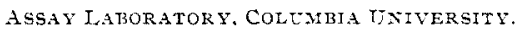

\title{
A MODIFICATION OF THE GUNNING METHOD FOR NITRATES.
}

BY JOHN FIELDS.

Received October 20, I896.

$\prod \begin{aligned} & \mathrm{HE} \text { full text of the official Gunning" method is as follows: } \\ & \text { "In a digestion flask, holding from } 250 \text { to } 500 \mathrm{cc} \text {., place }\end{aligned}$ from seven-tenths to three and five-tenths grams of the substance to be analyzed, according to the amount of nitrogen present. Add thirty to thirty-five $c c$. of salicylic acid mixture; namely, thirty cc. sulphuric acid to one gram of salicylic acid, shake until thoroughly mixed and allow to stand five to ten

1 Ann, chim, phys., [5], 8, 474 .

2 Bulletin 46, U. S. Dept. of Agr., p. I8. 
minutes, with frequent shaking; then add five grams sodium thiosulphate and ten grams of potassium sulphate. Heat very gently until frothing ceases, then heat strongly until nearly colorless. Dilute, neutralize, and distil as in the Gunning method."

This method has its advantages in that no heavy metals are added, such as zinc and mercury, which sometimes interfere with the distillation. It has, however, a few disadvantages which the following modification partially overcomes. When working with some materials, there is considerable trouble due to persistent frothing, and in some cases, it has taken six hours constant attention to get the digestion safely over this point. Moreover, unless the contents of the flask are diluted while still warm, there is a tendency for the sulphates to become hard and difficult of solution.

In the modification proposed, the following reagents are necessary :

I. Chemically pure sulphuric acid.

2. Salicylic acid.

3. Potassium sulphide.

The material containing the nitrates is weighed out into a digestion flask and thirty cc. sulphuric acid containing one gram salicylic acid are added, and gently heated to facilitate the solution of nitrates and prevent frothing later. While warm, six to seven grams of potassium sulphide are added in small portions, the flask being thoroughly shaken after each addition. It is then placed over a low flame and the heat rapidly increased until the acid mixture boils. No further attention is required and the digestion is usually complete at the end of an hour. When cold, the liquid is diluted and distilled in the usual manner.

The average difference between the results on sixty samples of fertilizers containing nitrates by the official method and the proposed modification was 0.02 per cent., those by the latter being higher.

The points of difference between the modification and the offcial modified Gunning are the following : 
I. The number of reagents used in the digestion is reduced from four to three.

2. Frothing is obviated and the operation requires no attention except turning up the lamps until full heat is secured.

3. The time of digestion is shortened.

4. Potassium sulphide is made to do double work by acting as a reducing agent instead of sodiun thiosulphate and then being converted into potassium hydrogen sulphate serving the end secured by adding potassium sulphate in the original method.

\section{THE SEPARATION OF ALKALOIDAL EXTRACTS.}

BY CHARIES PLATT.

Received Octoher zo, 18 gó.

$T \mathrm{HE}$ writer has found the accompanying simple device of great value in the separation of the annoying emulsions

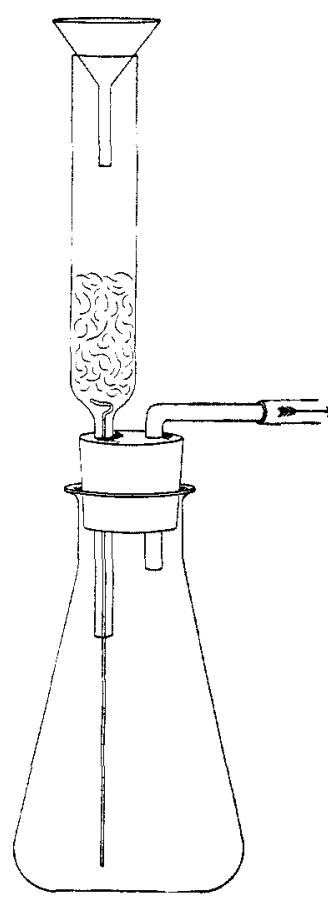
so often met with in alkaloidal anal$y$ sis, as, for instance, in the petroleum ether and benzene extractions of Dragendorff's method. The filtering tube is nineteen $\mathrm{cm}$. long, the upper $12.5 \mathrm{~cm}$. having an inside diameter of fourteen $\mathrm{mm}$., the lower contracted portion, an inside diam. eter of three mm. A stout platinum wire bent at the upper end is so placed as to pass through the constricted portion of the tube to the bottom of the eight-ounce Erlenmeyer flask. Washed cotton is firmly packed in the tube to a depth of about four $\mathrm{cm}$. and the apparatus, connected with a filter pump, is ready for use. The filtered liquids may finally be carefully poured into an ordinary separating funnel and manipulated as usual. By this method the most persistent emulsions are separated into their constituent liquids in as many minutes as ordinarily are required hours or days.

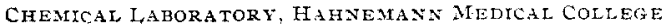

PhILADELPHIA. Pa. 